Original Article

\title{
POTENTIAL DRUG INTERACTIONS IN HYPERTENSIVE PATIENTS IN LIWA DISTRICT HOSPITAL, LAMPUNG BARAT, INDONESIA
}

\author{
ERNA YANTIa, ERNA KRISTINb, ALFI YASMINAc
}

aLiwa Hospital, Lampung Barat District, Lampung, Indonesia, bDepartment of Pharmacology and Therapy, Faculty of Medicine, Universitas Gadjah Mada, Yogyakarta, Indonesia, cDepartment of Pharmacology, Faculty of Medicine, Lambung Mangkurat University, Banjarmasin, Indonesia

Email: erna_kristin@yahoo.co.uk

Received: 19 Feb 2017 Revised and Accepted: 29 Apr 2017

\begin{abstract}
Objective: Patients with hypertension often suffer from other comorbidities, resulting in prescriptions of multiple drugs to treat the conditions. Multiple drug treatment is potentially associated with drug interactions. This aim of the study was to assess potential drug interactions in hypertensive patients in Liwa District Hospital.

Methods: The design of the study was cross-sectional. The prescriptions for in-patients with essential hypertension in the Internal Medicine Unit in Liwa District Hospital during April-December 2012 were collected. Potential drug interactions were analyzed with the Drug Interaction Facts version 4.0, and classified into minor, significant, and serious.
\end{abstract}

Results: A total of 60 hypertensive patients were included. They were prescribed 265 prescriptions, with a median total of 6 (range 1-21) drugs prescribed per prescription. There were 1616 potential drug interactions, with 6 (1-31) potential interactions per prescription. Most interactions (75.6\%) were classified as significant. Serious potential interactions were most common in the combinations of diltiazem-amlodipine and spironolactone-potassium chloride, while significant potential interaction may occur most often with the combinations of calcium chloride-amlodipine and bisoprolol-amlodipine.

Conclusion: Numerous potential drug interactions might occur in hypertensive patients, and most interactions were significant in severity. The largest proportion of the interactions occurred between antihypertensive agents and other drugs.

Keywords: Drug interaction, Hypertension, Antihypertensive agent

(C) 2017 The Authors. Published by Innovare Academic Sciences Pvt Ltd. This is an open access article under the CC BY license (http://creativecommons.org/licenses/by/4.0/) DOI: http://dx.doi.org/10.22159/ijpps.2017v9i6.18003

\section{INTRODUCTION}

Hypertension is still one of the most substantial challenges in healthcare in Indonesia. Based on Basic Health Survey 2013, the prevalence of hypertension was still high (25.8\%), with evidence of inadequate control despite many available antihypertensive agents [1]. Increasing age, gender, educational level, body mass index, smoking, alcohol drinking, and underlying diseases are associated with the prevalence of hypertension [2]. It has also been suggested that different areas with different socioeconomic status might have different prevalence, awareness, treatment, and control of hypertension [3]. Hypertension itself is problematic since it is the risk factor of many cardiovascular diseases [4, 5], and may lead to myocardial infarction, stroke, renal failure, and death. Preventive efforts are crucial to decrease the risk of these cardiovascular diseases. Better blood pressure measurement can increase awareness towards hypertension, facilitate treatment, better hypertension control, and better outcomes [6].

Antihypertensive agents are available to reduce hypertension, along with lifestyle management. The Eighth Joint National Committee (JNC 8) has published a guideline on the management of hypertension, including the treatment. Based on the guideline, treatment with antihypertensive agents is started with one antihypertensive drug class (usually thiazide, angiotensin converting enzyme inhibitor [ACEI], angiotensin-II receptor blocker [ARB], or calcium channel blocker [CCB]), and the response will determine whether to add the dose or to add another antihypertensive drug class [7]. Often patients with hypertension will need more than one antihypertensive agent [7, 8]. A strategy to increase the efficacy, acceptability and adherence to antihypertensive drugs is needed, for example with the fixed-dose combination $[9,10]$.

Due to the fact that hypertension is one of the risk factors of many cardiovascular diseases, the older a patient gets, the more comorbidity the patient might have. The elderly patients have their own complex situation. Multiple comorbidities lead to the prescription of multidrugs to treat these comorbidities, and this eventually leads to poly- pharmacy [11]. Therefore, not only hypertensive patients (particularly elderlies) would be prescribed many drugs for the treatment of hypertension itself, but also for treatment of the comorbidities [12]. There is a strong association between the number of drugs prescribed and potential drug interactions $[13,14]$.

There have been not many studies evaluating potential drug interactions in hypertensive patients in Indonesia. Therefore, this study was conducted with the aim to assess potential drug interactions in hypertensive patients in Liwa District Hospital.

\section{MATERIALS AND METHODS}

This cross-sectional study was conducted in the in-patients with essential hypertension in the Internal Medicine Unit in Liwa District Hospital during April-December 2012. All prescriptions for patients with essential hypertension in the Internal Medicine Unit were collected. Prescriptions for patients with secondary hypertension (renal hypertension, hypertension caused by drugs, endocrine disorder, and central nervous system disorder) were excluded.

Analysis of drug interaction was conducted using the Drug Interaction Facts version 4.0 from Wolters Kluwer Health (http:// reference. medscape.com/drug-interaction checker). The drug interactions were classified into three groups based on severity, namely, minor, significant, and serious (table 1).

Descriptive statistics were used to describe the characteristics of the patients and the number of potential drug interactions. Frequencies (or proportions) and medians with range were calculated for patient characteristics and drug interactions.

\section{RESULTS}

The present study included 60 hypertensive patients, who were prescribed 265 prescriptions. The median age of the patients was 53 
Table 1: Drug interaction facts software classification scheme of the levels of severity of drugs interactions*

\begin{tabular}{ll}
\hline Level of severity & Description \\
\hline 1 & Serious: an adverse effect can cause permanent damage or life risk. \\
2 & Significant: an adverse effect can harm and treatment is required. \\
3 & Minor: small or no clinical effect, with no treatment required. \\
\hline
\end{tabular}

* Drug Interaction Facts, version 4.0, 2006, by Wolters Kluwer Health. Electronic source: http://reference.medscape.com/drug-interactionchecker,

Table 2: Characteristics of patients in the study

\begin{tabular}{lll}
\hline Patient characteristic & Number of patients or value & \% \\
\hline Total number of patients & 60 & 100 \\
Total number of prescriptions & 265 & 100 \\
Median age (year), range & $53(32-90)$ & - \\
Sex & & 60 \\
Female & 36 & 40 \\
Male & 24 & - \\
Number of drugs prescribed per prescription, median (range) & $6(1-21)$ & \\
\hline
\end{tabular}

Table 3 describes the frequency and classification of potential drug interactions found in the prescriptions. In the 265 prescriptions, there were 1616 potential drug interactions, with a median of 6 (1-31) potential drug interactions per prescriptions. The severity of the potential drug interactions was mostly significant $(75.6 \%)$, while $4.4 \%$ and $0.8 \%$ were categorized as serious potential drug interactions and contraindications, respectively.

Table 3: Frequency, classification, and mechanisms of potential drug interactions

\begin{tabular}{|c|c|c|}
\hline Potential drug interactions & No. & $\%$ \\
\hline Number of potential drug interactions & 1616 & 100 \\
\hline Number of potential drug interactions per prescriptions, median (range) & $6(1-31)$ & \\
\hline \multicolumn{3}{|l|}{ Severity of drug interactions } \\
\hline Contraindication & 13 & 0.8 \\
\hline Serious & 71 & 4.4 \\
\hline Significant & 1222 & 75.6 \\
\hline Minor & 310 & 19.2 \\
\hline
\end{tabular}

Table 4: Description of potential drug interaction that is categorized as contraindication

\begin{tabular}{lll}
\hline $\begin{array}{l}\text { Drug interaction } \\
\text { (number of events) }\end{array}$ & Cases & Description \\
\hline $\begin{array}{l}\text { Ceftriaxone+calcium } \\
\text { chloride (13) }\end{array}$ & 8 & $\begin{array}{l}\text { Contraindicated in neonates if they require (or are expected to require) treatment with } \\
\text { calcium-containing intravenous solutions, including continuous calcium-containing } \\
\text { infusions such as parenteral nutrition because of the risk of precipitation of ceftriaxone- } \\
\text { calcium. The administration of intravenous ceftriaxone and intravenous calcium needs to be } \\
\text { separated by at least 48 h. However, in patients other than neonates, ceftriaxone and } \\
\text { calcium-containing solutions may be administered sequentially of one another if the } \\
\text { intravenous infusion lines are thoroughly flushed between infusions with a compatible fluid. }\end{array}$ \\
\hline
\end{tabular}

Table 5: Description of potential drug interactions that are categorized as serious

\begin{tabular}{|c|c|c|c|}
\hline $\begin{array}{l}\text { Drug interactions } \\
\text { (number of events) }\end{array}$ & Cases & Description & $\begin{array}{l}\text { Level of } \\
\text { severity }\end{array}$ \\
\hline Diltiazem+amlodipine (14) & 10 & $\begin{array}{l}\text { Diltiazem will increase the level or effect of amlodipine by affecting hepatic/intestinal } \\
\text { enzyme CYP3A4 metabolism. Diltiazem increases amlodipine exposure by } 60 \% \text {. }\end{array}$ & Serious \\
\hline Diltiazem+bisoprolol (11) & 9 & $\begin{array}{l}\text { Either increases the toxicity of the other by unspecified interaction mechanism. Can } \\
\text { increase the risk of bradycardia. }\end{array}$ & Serious \\
\hline $\begin{array}{l}\text { Spironolactone+potassium } \\
\text { chloride (14) }\end{array}$ & 6 & Spironolactone and potassium chloride both increase serum potassium. & Serious \\
\hline Losartan+captopril (10) & 4 & $\begin{array}{l}\text { Either increases the toxicity of the other by pharmacodynamic synergism. Dual } \\
\text { blockade of renin-angiotensin system increases risks of hypotension, hyperkalemia, } \\
\text { and renal impairment. }\end{array}$ & Serious \\
\hline Ketoprofen+ketorolac (5) & 4 & Either increases the toxicity of the other by pharmacodynamic synergism. & Serious \\
\hline Digoxin+bisoprolol (3) & 3 & $\begin{array}{l}\text { Either decreases the toxicity of the other by unspecified interaction mechanism. Can } \\
\text { increase the risk of bradycardia. }\end{array}$ & Serious \\
\hline Aluminum hydroxide+digoxin (2) & 2 & $\begin{array}{l}\text { Aluminum hydroxide will increase the level or effect of digoxin by increasing gastric } \\
\text { pH. Applies only to oral form of both agents. }\end{array}$ & Serious \\
\hline
\end{tabular}


The potential drug interactions categorized based on the severity are summarized in table $4,5,6$, and 7 . The most common potential drug interaction categorized as contraindication was ceftriaxone and calcium chloride, because of the risk of precipitation of ceftriaxonecalcium. Serious potential drug interactions were most common in the combinations of diltiazem-amlodipine and spironolactonepotassium chloride. Diltiazem may increase serum amlodipine level by affecting CYP3A4, while the combination of spironolactone and potassium chloride will potentially increase potassium level.
Significant potential drug interactions may occur most commonly with the combinations of calcium chloride-amlodipine and bisoprolol-amlodipine. Bisoprolol and amlodipine both will potentially increase antihypertensive channel blockade. Calcium chloride may decrease the effect of amlodipine. A minor potential drug interaction may occur most often with the combination of ranitidine and cyanocobalamin, due to the ranitidine effect in decreasing the serum level of cyanocobalamin by inhibiting gastrointestinal absorption.

Table 6: Description of potential drug interactions that are categorized as significant

\begin{tabular}{|c|c|c|c|}
\hline $\begin{array}{l}\text { Drug interactions } \\
\text { (number of events) }\end{array}$ & Cases & Description & $\begin{array}{l}\text { Level of } \\
\text { severity }\end{array}$ \\
\hline Calcium chloride+amlodipine (127) & 52 & Calcium chloride decreases effects of amlodipine by pharmacodynamics antagonism. & Significant \\
\hline Calcium chloride+bisoprolol (72) & 35 & Calcium chloride decreases effect of bisoprolol by unspecified interaction mechanism. & Significant \\
\hline Bisoprolol+amlodipine (92) & 35 & Bisoprolol and amlodipine both increase anti-hypertensive channel blocking. & Significant \\
\hline Losartan+potassium chloride(68) & 32 & Losartan and potassium chloride both increase serum potassium. & Significant \\
\hline Losartan+bisoprolol (76) & 32 & $\begin{array}{l}\text { Losartan and bisoprolol both increase serum potassium. Mechanism: } \\
\text { pharmacodynamic synergism. The risk of fetal compromise if given during pregnancy. }\end{array}$ & Significant \\
\hline Bisoprolol+potassium chloride (69) & 32 & Bisoprolol and potassium chloride both increase serum potassium. & Significant \\
\hline Ketorolac + potassium chloride (32) & 16 & Ketorolac and potassium chloride both increase serum potassium. & Significant \\
\hline $\begin{array}{l}\text { Potassium chloride+furosemide } \\
\text { (39) }\end{array}$ & 15 & $\begin{array}{l}\text { Potassium chloride increases and furosemide decreases serum potassium. Effect of } \\
\text { interaction is not clear. }\end{array}$ & Significant \\
\hline Bisoprolol+furosemide (19) & 11 & $\begin{array}{l}\text { Bisoprolol increases and furosemide decreases serum potassium. Effect of } \\
\text { interaction is not clear. }\end{array}$ & Significant \\
\hline Ketorolac+bisoprolol (18) & 10 & $\begin{array}{l}\text { Bisoprolol and ketorolac both increase serum potassium. Ketorolac decreases } \\
\text { effects of bisoprolol by pharmacodynamic antagonism. }\end{array}$ & Significant \\
\hline Captopril+potassium chloride (24) & 10 & $\begin{array}{l}\text { Captopril increases levels of potassium chloride by decreasing elimination. The risk } \\
\text { of hyperkalemia. }\end{array}$ & Significant \\
\hline Bisoprolol+diltiazem (12) & 10 & Bisoprolol and diltiazem both increase anti-hypertensive channel blocking. & Significant \\
\hline $\begin{array}{l}\text { Aluminum hydroxide+bisoprolol } \\
\text { (17) }\end{array}$ & 10 & $\begin{array}{l}\text { Aluminum hydroxide decreases levels of bisoprolol by inhibition of gastrointestinal } \\
\text { absorption. Applies only to oral form of both agents. These drugs need to be } \\
\text { separated by } 2 \mathrm{~h} \text {. }\end{array}$ & Significant \\
\hline Omeprazole+losartan (17) & 9 & $\begin{array}{l}\text { Omeprazole will increase the level or effect of losartan by affecting hepatic enzyme } \\
\text { CYP2C9/10 metabolism. May inhibit the conversion of losartan to its active } \\
\text { metabolite E-3174. The importance of interaction not established; the individual } \\
\text { therapeutic response needs to be monitored to determine losartan dosage. }\end{array}$ & Significant \\
\hline Calcium chloride+diltiazem (14) & 9 & Calcium chloride decreases effects of diltiazem by pharmacodynamic antagonism. & Significant \\
\hline Amlodipine+diltiazem (14) & 9 & Amlodipine and diltiazem both increase anti-hypertensive channel blocking. & Significant \\
\hline Losartan+ketorolac (27) & 8 & $\begin{array}{l}\text { Either increases the toxicity of the other. May result in renal function deterioration, } \\
\text { particularly in elderly or volume depleted individuals. } \\
\text { Ketorolac decreases effects of losartan by pharmacodynamic antagonism. NSAIDs } \\
\text { decrease synthesis of vasodilating renal prostaglandins, and thus affect fluid } \\
\text { homeostasis and may diminish antihypertensive effect. }\end{array}$ & Significant \\
\hline Losartan+furosemide (21) & 8 & $\begin{array}{l}\text { Losartan increases and furosemide decreases serum potassium. Effect of } \\
\text { interaction is not clear. }\end{array}$ & Significant \\
\hline
\end{tabular}

Table 7: Description of potential drug interactions that are categorized as minor

\begin{tabular}{|c|c|c|c|}
\hline $\begin{array}{l}\text { Drug interactions } \\
\text { (number of events) }\end{array}$ & Cases & Description & $\begin{array}{l}\text { Level of } \\
\text { severity }\end{array}$ \\
\hline Ranitidine+cyanocobalamin (49) & 23 & $\begin{array}{l}\text { Ranitidine decreases levels of cyanocobalamin by inhibition of GI absorption. } \\
\text { Applies only to oral form of both agents. }\end{array}$ & Minor \\
\hline Furosemide+calcium chloride (41) & 15 & Furosemide decreases levels of calcium chloride by increasing renal clearance. & Minor \\
\hline Furosemide+thiamine (10) & 7 & Furosemide decreases levels of thiamine by increasing renal clearance. & Minor \\
\hline Dexamethasone+calcium chloride (18) & 7 & Dexamethasone decreases levels of calcium chloride by increasing elimination. & Minor \\
\hline Spironolactone+calcium chloride (14) & 6 & Spironolactone decreases levels of calcium chloride by increasing renal clearance. & Minor \\
\hline Dexamethasone+amlodipine (11) & 6 & $\begin{array}{l}\text { Dexamethasone will decrease the level or effect of amlodipine by affecting } \\
\text { hepatic/intestinal enzyme CYP3A4 metabolism. }\end{array}$ & Minor \\
\hline Omeprazole+cyanocobalamin (10) & 5 & $\begin{array}{l}\text { Omeprazole decreases levels of cyanocobalamin by inhibition of GI absorption. } \\
\text { Applies only to oral form of both agents. }\end{array}$ & Minor \\
\hline Hydrochlorothiazide+ranitidine (8) & 5 & $\begin{array}{l}\text { Hydrochlorothiazide will increase the level or effect of ranitidine by basic } \\
\text { (cationic) drug competition for renal tubular clearance. }\end{array}$ & Minor \\
\hline
\end{tabular}

\section{DISCUSSION}

In this study, it was found that many potential drug interactions might occur in patients with hypertension, and most potential drug interactions were categorized as significant. The interaction might not only occur between antihypertensive agents themselves or between antihypertensive agent and other drugs, but also among other groups outside of antihypertensive agents, due to the concomitant diseases that usually occur in patients with hypertension in the age range included in this study (median age 53, range 32-90 y), as shown by the number of drugs prescribed per prescription (median number 6, range 1-21). 
Several studies on potential drug interactions in hypertensive patients have been done. A previous study in India [15] showed that, from 899 hypertensive patients in the study, 87\% were at risk of potential drug interactions, while in our study every patient was at risk of having potential drug interactions. In that study, $71.5 \%$ prescriptions were potentially having at least one drug interaction, with a total of 918 potential drug interactions. Another study was conducted in Croatia in elderly patients with arterial hypertension [16] and this study found $90.6 \%$ patients would potentially have clinically significant drug interactions, with the median number of significant potential drug interaction, was 4 (range 1-19). A study in Brazil also showed high potential drug interactions (93\%) in patients with arterial hypertension and/or diabetes [17]. Another study in the United States of America suggested that potential drug interactions among hypertensive patients did not only occur in elderly patients, but also in younger patients. In that study, $23-48 \%$ patients were potentially had significant drug interactions [18].

The considerable number of potential drug interactions in this study warrants some concern, with a median of 6 potential drug interactions might occur per prescriptions, with most proportion was categorized as significant, which is similar to the results of Kothari's study that also showed that the potential drug interactions were mostly (95.4\%) in significant category [15].

Potential drug interactions in hypertensive patients in this study most commonly might occur in the combination of antihypertensive agents with other drugs. There were also many cases with a combination of antihypertensive agents that were categorized as significant, such as the combination of bisoprolol-amlodipine, losartan-bisoprolol, bisoprolol-furosemide, bisoprolol-diltiazem, amlodipine-diltiazem, and losartan-furosemide. The previous study in India also showed that the most common combination that might lead to drug interaction in hypertensive patients were between antihypertensive agents, namely, atenolol-amlodipine and metoprolol-amlodipine [15]. The Croatian study suggested that antihypertensive agents were responsible for $51 \%$ potential drug interaction, with a combination of nonsteroidal anti-inflammatory drugs (NSAID) and antihypertensive agents and combination between ACEI and thiazide or loop diuretic as the most common potential drug interactions [16]. The study in Brazil indicated that the most frequent potential drug interaction was for the combination of acetylsalicylic acid-enalapril and glibenclamide-HCT [17]. Another study from India showed that potential drug interactions might occur in hospitalized patients who received amlodipine-atenolol combination or amlodipine-diclofenac combination [19].

These potential drug interactions not only would lead to failure of treatment but also might introduce the risk of adverse effects. Clinical and laboratory monitoring might be needed to assess these potential drug interactions, so that a dose adjustment, discontinuation, or another risk-modification strategy can be performed [20]. Computerised clinical decision support system can be used to prevent potential drug interactions. This system is increasingly used in hospitals to support evidence-based decision making by physicians and pharmacists [21-23].

There are several limitations of this study that need to be considered when interpreting the results. This study only assessed potential drug interactions but did not evaluate the actual adverse events occurred due to these potential drug interactions. However, it is not possible or ethical to assess the adverse events of a potential drug interaction without conducting an intervention to the potential drug interaction. Another limitation is that the list of drug interactions in the software is based on available evidence to date. Therefore, a drug that is available longer in the market will have more information on interactions compared to the newer ones, leading to more interactions occurred with older drugs compared to the newer drugs.

\section{CONCLUSION}

In conclusion, this study showed that many potential drug interactions might occur in patients hospitalized for hypertension, with the largest proportion of the interactions were significant in severity. Most interactions occurred between antihypertensive agents themselves and between the antihypertensive agent and other drugs. Serious potential drug interaction might occur most commonly with diltiazem-amlodipine combination or with spironolactone-potassium chloride combination; while significant potential drug interaction might occur most commonly with calcium chloride-amlodipine combination or with the bisoprolol-amlodipine combination.

\section{ACKNOWLEDGEMENT}

The authors would like to acknowledge the considerable support from Liwa Hospital for sharing their data for this research.

\section{AUTHOR CONTRIBUTION}

Erna Yanti planned the study and collected the data. Erna Kristin planned the study, conducted the analyses, wrote the drafts of the manuscript, as well as edited and agreed on the final version of the manuscript. Alfi Yasmina wrote the drafts of the manuscript and agreed on the final version of the manuscript.

\section{CONFLICTS OF INTERESTS}

All authors have no conflicts of interests to declare.

\section{REFERENCES}

1. Ministry of the Health Republic of Indonesia. Information: Hypertension. Jakarta: Kemenkes RI; 2014.

2. Thawornchaisit P, de Looze F, Reid CM, Seubsman SA, Sleigh A. Thai Cohort Study Team. Health risk factors and the prevalence of hypertension: cross-sectional findings from a national cohort of 87,143 Thai Open University students. Glob J Health Sci 2013;5:126-41.

3. Dong F, Wang D, Pan L, Yu Y, Wang K, Li L, et al. Disparities in hypertension prevalence, awareness, treatment and control between bouyei and han: results from a bi-ethnic health survey in developing regions from South China. Int J Environ Res Public Health 2016;13:233.

4. Omole MK, Oke GO. A ten-year study of the pharmacotherapy of hypertension at a tertiary hospital in South Western Nigeria. Asian J Pharm Clin Res 2012;5 Suppl 1:26-9.

5. Kousalya K, Chirumamilla S, Manjunath S, Ramalakshmi S, Saranya P, Chamundeeswari D. Prescribing trend of antihypertensive drugs in hypertensive and diabetic hypertensive patients. Asian J Pharm Clin Res 2012;5:22-3.

6. Modesti PA, Perruolo E, Parati G. Need for better blood pressure measurement in developing countries to improve prevention of cardiovascular disease. JEpidemiol 2015;25:91-8.

7. James PA, Oparil S, Carter BL, Cushman WC, DennisonHimmelfarb C, Handler J, et al. 2014 evidence-based guideline for the management of high blood pressure in adults: report from the panel members appointed to the Eighth Joint National Committee (JNC 8). JAMA 2014;311:507-20.

8. Byrd JB, Zeng C, Tavel HM, Magid DJ, O'Connor PJ, Margolis KL, et al. Combination therapy as initial treatment for newly diagnosed hypertension. Am Heart J 2011;162:340-6.

9. Lewanczuk R, Tobe SW. More medications, fewer pills: combination medications for the treatment of hypertension. Can J Cardiol 2007;23:573-6.

10. Hess G, Hill J, Lau H, Dastani H, Chaudhari P. Medication Utilization patterns and hypertension-related expenditures among patients who were switched from fixed-dose to freecombination antihypertensive therapy. P T 2008;33:652-66.

11. Mannucci PM, Nobili A. REPOSI Investigators. Multimorbidity and polypharmacy in the elderly: lessons from REPOSI. Intern Emerg Med 2014;9:723-34.

12. Song J, Sheng CS, Huang QF, Li LH, Ma CS, Guo XH, et al. Management of hypertension and diabetes mellitus by cardiovascular and endocrine physicians: a China registry. J Hypertens 2016;34:1648-53.

13. Johnell K, Klarin I. The relationship between a number of drugs and potential drug-drug interactions in the elderly: a study of over 600,000 elderly patients from the swedish prescribed drug register. Drug Saf 2007;30:911-84.

14. Hanlon JT, Perera S, Newman AB, Thorpe JM, Donohue JM, Simonsick EM, et al. Potential drug-drug and drug-disease interactions in well-functioning community-dwelling older adults. J Clin Pharm Ther 2017;42:228-33. 
15. Kothari N, Ganguly B. Potential drug-drug interactions among medications prescribed to hypertensive patients. J Clin Diagn Res 2014;8:HC01-4.

16. Bacic-Vrca V, Marusic S, Erdeljic V, Falamic S, Gojo-Tomic N, Rahelic D. The incidence of potential drug-drug interactions in elderly patients with arterial hypertension. Pharm World Sci 2010;32:815-21.

17. Neto VC, Garcia VP, de Santa Helena ET. Possible pharmacological interactions in hypertensive and/or diabetic elderly in family health units at Blumenau (SC). Brazilian J Pharm Sci 2010;46:795-804.

18. Carter BL, Lund BC, Hayase N, Chrischilles E. The extent of potential antihypertensive drug interactions in a medicaid population. Am J Hypertens 2002;15:953-7.

19. Nag KA, Umesh M, Churi S. Assessment of drug-drug interactions in hospitalized patients in India. Asian J Pharm Clin Res 2011;4 Suppl 1:62-5.

20. Uijtendaal EV, van Harssel LL, Hugenholtz GW, Kuck EM, Zwartvan Rijkom JE, Cremer OL, et al. Analysis of potential drug-drug interactions in medical intensive care unit patients. Pharmacotherapy 2014;34:213-9.

21. Robertson J, Walkom E, Pearson SA, Hains I, Williamsone M, Newby D. The impact of pharmacy computerized clinical decision support on prescribing, clinical and patient outcomes: a systematic review of the literature. Int J Pharm Pract 2010;18:69-87.

22. Nabovati E, Vakili-Arki H, Taherzadeh Z, Saberi MR, Medlock S, Abu-Hanna A, et al. Information technology-based interventions to improve drug-drug interaction outcomes: a systematic review on features and effects. J Med Syst 2017;41:12.

23. Ferrández $\mathrm{O}$, Urbina $\mathrm{O}$, Grau S, Mateu-de-Antonio J, MarinCasino M, Portabella J, et al. Computerized pharmacy surveillance and alert system for drug-related problems. J Clin Pharm Ther 2017;42:201-8.

\section{How to cite this article}

- $\quad$ Erna Yanti, Erna Kristin, Alfi Yasmina. Potential drug interactions in a hypertensive patient in liwa district hospital, lampung barat, Indonesia. Int J Pharm Pharm Sci 2017;9(6):134-138. 